\title{
Dietary herring improves plasma lipid profiles and reduces atherosclerosis in obese low-density lipoprotein receptor-deficient mice
}

\author{
BRITT G. GABRIELSSON ${ }^{1}$, JOHANNES WIKSTRÖM ${ }^{2}$, ROBERT JAKUBOWICZ ${ }^{3}$, SOFIA K. MARMON ${ }^{1}$, \\ NILS-GUNNAR CARLSSON ${ }^{1}$, NINA JANSSON ${ }^{3}$, LI-MING GAN ${ }^{2}$, INGRID UNDELAND ${ }^{1}$, \\ MALIN LÖNN ${ }^{4}$, AGNETA HOLMÄNG $^{3}$ and ANN-SOFIE SANDBERG ${ }^{1}$
}

\begin{abstract}
${ }^{1}$ Food Science, Department of Chemical and Biological Engineering, Chalmers University of Technology, SE-412 96 Gothenburg; ${ }^{2}$ AstraZeneca R\&D Bioscience, SE-431 83 Mölndal; ${ }^{3}$ Physiology, Institute of Neuroscience and Physiology, Sahlgrenska Academy, University of Gothenburg; ${ }^{4}$ Clinical Chemistry and Transfusion Medicine, Institute of Biomedicine, Sahlgrenska Academy, University of Gothenburg, SE-405 30 Gothenburg, Sweden
\end{abstract}

Received September 20,2011; Accepted October 25, 2011

DOI: $10.3892 / \mathrm{ijmm} .2011 .856$

\begin{abstract}
Diet is a significant modifiable risk factor for cardiovascular disease and high fish intake has been associated with vascular health in population studies. However, intervention studies have been inconclusive. In this study, male low-density lipoprotein receptor-deficient mice were given 16-week high fat/high sucrose diets, supplemented with either minced herring fillets or minced beef. The diets were matched in total fat and cholesterol content; taurine content and fatty acid composition was analysed. Body weights were recorded throughout the study; plasma lipids were analysed at week 8 and 16. Body composition and adipocyte size were evaluated at study end. Atherosclerosis was evaluated at week 12 (ultrasound) and at termination (en face histology). Herring-fed mice had a higher proportion of long-chain n-3 polyunsaturated fatty acids in the hepatic triacylglycerides (TAG) and phospholipid fractions. The herring-fed mice had increased body weight $(\mathrm{P}=0.007)$, and reduced epididymal adipocyte size $(\mathrm{P}=0.009)$, despite similar food intake and body composition as the beef-fed mice. The herring-fed mice had lower plasma TAG and verylow-density lipoprotein (VLDL)-cholesterol concentrations throughout the study (TAG; P=0.0012 and 0.004, VLDLcholesterol; $\mathrm{P}=0.006$ and 0.041 , week 8 and 16 , respectively). At week 16, the herring-fed had higher plasma concentrations of HDL-cholesterol $(\mathrm{P}=0.004)$ and less atherosclerotic lesions in the aortic arch $(\mathrm{P}=0.007)$ compared with the beef-fed mice.
\end{abstract}

Correspondence to: Dr Britt G. Gabrielsson, Food Science, Department of Chemical and Biological Engineering, Chalmers University of Technology, SE-412 96 Gothenburg, Sweden E-mail: brittg@chalmers.se

Key words: low-density lipoprotein receptor-deficient, en face histology, lipoprotein particle cholesterol profile, herring
In conclusion, dietary herring in comparison to beef markedly improved vascular health in this mouse model, suggesting that herring provides an added value beyond its content of macronutrients.

\section{Introduction}

The global increase in welfare-related diseases is largely caused by changes in lifestyle, including increased consumption of energy-dense foods with high content of simple carbohydrates and saturated fats (1). Epidemiological and cohort studies show that diets rich in red or processed meats and refined carbohydrates are related to an increased risk for chronic welfare diseases. In contrast, healthy aging is associated with high dietary intake of fish, legumes, vegetables and whole grain (2-5). In particular, both morbidity and mortality in cardiovascular disease (CVD) is reduced with high fish consumption (6-8). Often this association is explained by the long-chain n-3 polyunsaturated fatty acids (PUFA) present in oily fish $(9,10)$. However, epidemiological and large cohort studies do not normally differentiate between oily or lean fish species. That fact that fish, including lean fish species, also contain other bioactive compounds which can contribute to the health benefits of high fish intake has in recent years become of increasing interest (11-15).

We have previously shown that herring-intake 5 times per week for 6 weeks increased plasma high-density lipoprotein (HDL)-concentrations in overweight men (16). In a cross-sectional study of 61-year-old men, we found that plasma eicosapentaenoic acid (EPA), a long-chain n-3 PUFA, was inversely related to intima-media thickness, a marker for subclinical atherosclerosis (17). In the present study, the effects of long-term fish intake on the progression of atherosclerosis and plasma lipid levels were investigated using the low-density lipoprotein receptor-deficient $\left(L d l r^{--}\right)$mouse model (18). Disease progression in this model is known to be dependent on the dietary content of cholesterol (19) and of fat (20). In humans, 
mutations of the LDLR gene are associated with familial hypercholesterolemia (21). Similar to the $L d l r^{-1-}$ mouse, this condition is characterized by high circulating levels of LDL and a susceptibility to develop atherosclerotic plaques in the aortic root (22). Moreover, measures reflecting dietary intake of fish were inversely correlated to serum triacylglyceride (TAG) and cholesterol concentrations in familial hypercholesterolemia subjects (23).

Male $L d l r^{-/}$mice were fed a 16-week energy-dense (high fat/high sucrose) diet, supplemented with either minced herring fillets or minced beef. The 2 diets were matched in total fat and cholesterol content. The present study shows the physiological effects of dietary herring vs. beef on body composition, adipocyte size, lipid profiles and atherosclerosis. Transcriptome data derived from a subset of these animals ( $\mathrm{n}=3$ per diet group) has previously been published (24).

\section{Materials and methods}

Animals. Seven-week-old male $L d l r^{-/}$mice (Jackson Laboratories stock no. 002207) were obtained from Charles River Laboratories (Sulzfeld, Germany). Animals were kept under standardized conditions with free access to water and chow; lights were on between 7 am and $7 \mathrm{pm}$. The mice were randomly assigned to 2 groups ( $\mathrm{n}=14$ per group, 4-5 mice per cage) and housed for 1 week with standard rodent chow to acclimate to our animal facilities. Data from 1 mouse fed the herring diet was excluded from the analysis due to fighting followed by severe weight-loss and subsequent isolation. The study was approved by the local Animal Ethics Committee of the University of Gothenburg, Gothenburg, Sweden.

Diets. Herring fillets (Clupea harengus), kindly provided by Paul Mattsson AB (Ellös, Sweden), were minced at $4^{\circ} \mathrm{C}$ with a food processor (KitchenAid, St. Joseph, MI, USA); lean minced beef was obtained from the local butcher. The fat content in the minced herring was $9.3 \%(\mathrm{w} / \mathrm{w})$ and the minced beef was adjusted to the same fat content by addition of minced, very lean sirloin. The minced herring fillets and beef were stored in $500 \mathrm{~g}$ portions at $-80^{\circ} \mathrm{C}$ until use. The diets were prepared as follows; $154 \mathrm{~g}$ butter, $162 \mathrm{~g}$ sugar, $184 \mathrm{~g}$ wheat flour and $10 \mathrm{~g}$ Vitamin mix (Harlan Teklad CA40060, The Netherlands) was made into a dough, followed by addition of $500 \mathrm{~g}$ minced herring or beef, and mixing. The mixture was baked in $200 \mathrm{~g}$ portions for $4 \mathrm{~min}$ at $650 \mathrm{~W}$ in a microwave oven. The estimated water loss was 14.3 and $15.1 \%$, respectively. The diets were frozen in $50 \mathrm{~g}$ portions wrapped in plastic foil. Table I shows macronutrient and fatty acid composition of the two diets. The total lipid contents of the starting materials; minced beef and herring fillets, as well as the final diets were analysed gravimetrically in triplicate (25). The fatty acid composition of total lipids from each diet was analysed as described below. The cholesterol content of the diets was analysed before transmethylation by GC using the HP-1 Ultra column. A known amount of 5- $\alpha$ cholesterone was added as an internal standard to allow quantification. Contents of protein, water and taurine content were measured by Eurofins Food and Agro Sweden AB (Lidköping, Sweden). The total protein was measured by the Kjeldahl method, the water content by gravimetry, before and after freeze-drying, and free taurine by HPLC (ISO 13903: 2005).
Experimental protocol. The diet intervention started when the mice were 8 -weeks-old and continued for 16 weeks. The animals were weighed weekly; food intake was measured per cage during 2 consecutive days at weeks $4,5,6,8$ and 11. Blood was taken from the tail vein at week 8 for analysis of plasma cholesterol and TAG concentrations. Plasma was obtained by centrifugation at $4^{\circ} \mathrm{C}$ of EDTA whole blood $(10 \mathrm{~min} ; 10,000 \mathrm{x} \mathrm{g})$ and aliquots were stored at $-80^{\circ} \mathrm{C}$. Body composition was measured at week 15 . At the end of the experiment, the mice were sacrificed on 2 consecutive days; food was removed at $6 \mathrm{am}, 3 \mathrm{~h}$ before start of termination, and mice were selected randomly and alternatively from each diet group at both days. The mice were given lethal intraperitoneal injections of sodium pentobarbital and blood was drawn from the left ventricle followed by perfusion with phosphatebuffered saline (PBS, pH 7.4). Heart and aorta were dissected to the iliac bifurcation and fixed in $4 \%$ paraformaldehyde for subsequent en face evaluation. Adipose tissue biopsies from the mesenteric and epididymal depots were placed in MEM medium (at approximately $30^{\circ} \mathrm{C}$ ) for analysis of adipocyte size. Livers were frozen in liquid nitrogen and stored at $-80^{\circ} \mathrm{C}$.

Dual energy X-ray absorptiometry (DXA). At week 15 , body composition was measured in mice anesthetized with isofluorane (Baxter, Deerfield, IL, USA) using a Lunar PIXImus densitometer (Lunar Corp, Madison, WI, USA) as previously described (26).

Determination of adipocyte size. Adipocytes were isolated and mean adipocyte diameter was determined by computerized image analysis as described previously using Leica QWin V3 software (Leica Microsystems, Wetzlar, Germany) (27). Briefly, the cell suspension was placed between a siliconised glass slide and a coverslip and transferred to the microscope stage (DM6000B, Leica Microsystems; 5X objective). Twelve random visual fields were photographed with a CCD camera (DFC320, Leica Microsystems). Uniform microspheres $98.00 \mu \mathrm{m}$ in diameter (Dynal, Invitrogen Corporation, Oslo, Norway) served as a reference.

Ultrasound. The brachiocephalic artery and aortic arch were visualized in 2 different projections, a long-axis view and a cross-sectional short-axis view in line with a previously published protocol (28). According to the published data, for measurements of aortic intima-media thickness, intra- and inter-observer variability is $4.7 \%$ and $6.7 \%$, respectively. For plaque area measurements, the corresponding values are $8.2 \%$ and $10 \%$, respectively. To minimize the user dependency, all measurements were performed by one operator blinded to the animal identity and treatment. Loops of at least 100 frames were stored in each projection. The frame with the largest plaque in each projection was chosen for off-line, blinded measurements.

Quantification of the atherosclerotic lesion area by en face histology. The aortas were prepared and analysed en face as previously described (29). Briefly, aortas were dissected free from adipose tissue, cut open along the longitudinal axis and pinned to silicon-coated plates. Lipids were stained with Sudan IV and images were recorded. Image analysis was performed blinded and the outline of the aorta and plaque 
Table I. Macronutrient content and fatty acid composition of the diets. Major fatty acids in each class are shown as mean \pm SE, $\mathrm{n}=3$.

\begin{tabular}{|c|c|c|}
\hline Macronutrient & Herring diet & Beef diet \\
\hline Carbohydrates $(\mathrm{g} / 100 \mathrm{~g})^{\mathrm{a}}$ & 34.8 & 34.8 \\
\hline Protein $(\mathrm{g} / 100 \mathrm{~g})$ & 13.7 & 15.3 \\
\hline Taurine (mg/100g) & 81 & 28 \\
\hline Fat $(g / 100 g)$ & $21.5 \pm 0.4$ & $21.6 \pm 1.2$ \\
\hline Cholesterol (mg/100g) & $74 \pm 2$ & $74 \pm 1$ \\
\hline Saturated fatty acids (mole\%), total & $64.0 \pm 1.0$ & $66.8 \pm 1.8$ \\
\hline Myristic acid (14:0) & $12.4 \pm 0.2$ & $10.3 \pm 1.6$ \\
\hline Palmitic acid (16:0) & $32.9 \pm 0.5$ & $35.9 \pm 0.2$ \\
\hline Stearic acid (18:0) & $9.0 \pm 0.1$ & $12.4 \pm 0.1$ \\
\hline Monounsaturated fatty acids (mole\%), total & $27.5 \pm 1.0$ & $29.8 \pm 2.0$ \\
\hline Oleic acid $(18: 1 n-9)$ & $20.4 \pm 0.9$ & $24.7 \pm 0.3$ \\
\hline Gondoic acid (20:1n-9) & $1.3 \pm 0.2$ & ND \\
\hline Cetoleic acid $(22: 1 n-11)$ & $2.1 \pm 0.1$ & ND \\
\hline Polyunsaturated fatty acids (mole\%), total & $8.2 \pm 0.1$ & $3.3 \pm 0.1$ \\
\hline Linoleic acid (LA; 18:2n-6) & $2.7 \pm 0.1$ & $2.5 \pm 0.0$ \\
\hline Alpha-linolenic acid (ALA; 18:3n-3) & $0.54 \pm 0.04$ & $0.77 \pm 0.12$ \\
\hline Arachidonic acid (AA; 20:4n-6) & $0.09 \pm 0.01$ & $0.13 \pm 0.01$ \\
\hline EPA $(20: 5 n-3)$ & $2.0 \pm 0.0$ & ND \\
\hline DHA $(22: 6 n-3)$ & $2.9 \pm 0.0$ & ND \\
\hline
\end{tabular}

a'Data calculated from the Danish Food Composition Databank, version 7.0, 2008 (http://www.foodcomp.dk/); ND, not detected.

lesion areas in the aortic arch, thoracic and abdominal aorta sections was defined manually. Aortas from 12 and 11 beefand herring-fed animals, respectively, were analysed. The extent of atherosclerosis was expressed as the percentage of lesion area to the total aortic area.

Quantitative lipid profiling. Frozen liver biopsies were weighed and homogenized in 10X volumes of phosphate-buffered saline (PBS; $10 \mathrm{mM} \mathrm{P}_{\mathrm{i}}, \mathrm{pH}$ 7.4). An aliquot of $100 \mu \mathrm{l}$ was removed from each sample for TAG analysis (see below) and the remaining parts of the homogenates were freeze-dried and weighed. Total lipids were extracted with chloroform-methanol according to the Folch method (30). Hepatic cholesterol content was analysed before transmethylation of the neutral lipid fraction as described above in the diets section. TAG and phospholipids were subsequently isolated using solid-phase extraction (31). A known amount of internal standard, 23:0 (Larodan, Malmö, Sweden), was added to the samples before the fatty acids were transmethylated for $1 \mathrm{~h}$ at $80^{\circ} \mathrm{C}$ using $10 \%$ acetyl chloride in methanol. The resulting fatty acid methyl esters (FAME) were separated on a Hewlett-Packard 5890 GC (Waldbronn, Germany) equipped with a flame ionization detector, using a HP1 Ultra capillary column (50 m x $0.32 \mathrm{~mm}$, film $0.52 \mu \mathrm{m}$; Agilent Technologies, Stockholm, Sweden) or a DB-Wax capillary column (30 m x $0.25 \mathrm{~mm}, 0.25 \mu \mathrm{m}$; Thomas Scientific, NJ, USA). The fatty acids were identified by comparison with pure FAME references (20:4n-6, 20:5n-3, 22:6n-3; Larodan) or FAME-mixes (Me-100 and Me-92; Larodan).
Plasma lipids. Plasma TAG and total cholesterol concentrations were determined enzymatically with Konelab autoanalyser version 2.0. Lipoprotein particles from pooled plasma samples (25 $\mu 1$ per animal; 3 animals per pool; 3 separate pools per group) were fractionated by the SMART LC-system (Pharmacia Biotech, Uppsala, Sweden) using a Superose- 6 column, followed by measurements of cholesterol in the fractions.

Statistical analysis. Data are presented as mean \pm SE. Statistical analysis was performed with the SPSS 16.0 software (SPSS Inc., Chicago, IL, USA) using an unpaired t-test. A value of $\mathrm{P}<0.05$ was considered statistically significant and adjusted according to Bonferroni-Holm (32) when appropriate.

\section{Results}

Diets and body weights. Diet composition data is shown in Table I; the diets were matched in total fat and cholesterol contents whereas the amount of taurine was approximately 3 -fold higher in the herring diet. The total amount saturated fatty acids (SFA) and monounsaturated fatty acids (MUFA) were similar, but differed in different fatty acids; the proportion of palmitic (16:0) and stearic acid (18:0) were higher in the beef diet as was oleic acid (18:1n-9). As expected, the herring diet contained a higher proportion of long-chain n-3 PUFA compared with the beef diet. Food intake measurements showed no difference in energy intake between the diet groups ( $2.2 \pm 0.1$ vs. $2.1 \pm 0.2 \mathrm{~kJ} / \mathrm{g}$ body weight for the beef and herring 
A

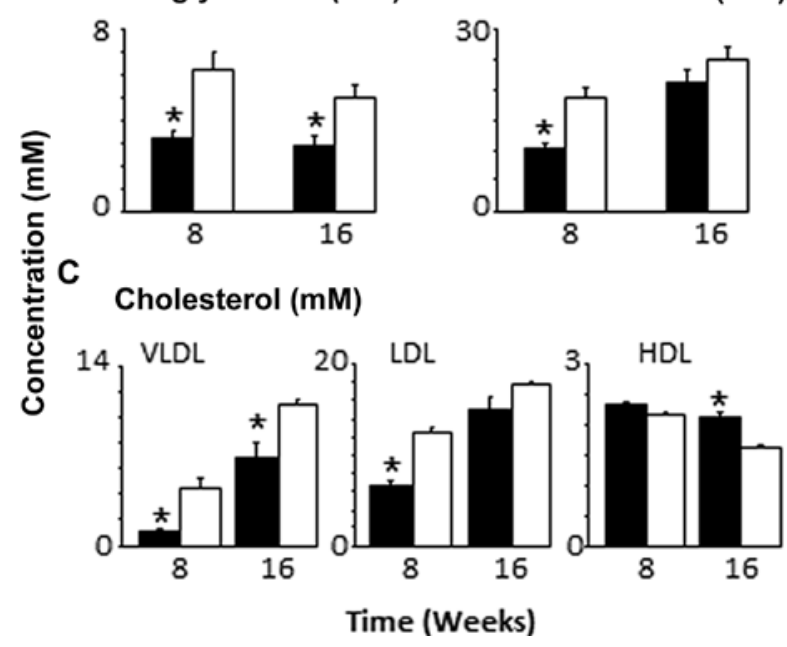

Figure 1. Plasma concentration of (A) triglycerides and (B) total cholesterol were measured at week 8 and at week 16 in mice fed herring (black bars) or beef (open bars). Values are shown as mean \pm SE ( $n=14$ and 13, beef and herring, respectively). (C) Lipoprotein particles from pooled samples $(n=3$ per diet group and time-point, where each pool consisted of plasma from 3 animals) were fractionated by FPLC and cholesterol were measured in the fractions. Significant differences were tested using unpaired t-test.

diets, respectively). The food intake corresponded to a daily dose of EPA plus DHA of 39-46 mg/day in the mice fed the herring diet.

All mice increased their weight during the study period. The mean body weight of the beef-fed mice was about $90 \%$ of that of the herring-fed mice from week 7 and onwards $(\mathrm{P}<0.05$; $31.7 \pm 0.7$ vs. $34.7 \pm 4.3 \mathrm{~g}$, for the beef- and herring-fed mice, respectively). There was no difference in body composition at week 15 between the 2 groups (lean body mass $60.1 \pm 1.9$ vs. $59.2 \pm 0.7 \%$; body fat mass $40.0 \pm 1.9$ vs. $40.8 \pm 0.7 \%$, for beefand herring-fed mice, respectively).

Plasma lipid concentrations. Fig. 1A and 1B show the plasma TAG and total cholesterol concentrations at weeks 8 and 16. At week 8, plasma TAG and total cholesterol concentrations were about $50 \%$ lower in the herring-fed mice compared with the beef-fed mice ( $\mathrm{P}=0.001$ and $\mathrm{P}<0.001$, respectively). At week 16, the plasma TAG concentration remained lower in the herring-fed mice $(\mathrm{P}=0.004)$, whereas the total cholesterol concentration was similar to that of beef-fed mice (NS). Analysis of plasma lipoprotein particles showed distinctly different patterns (Fig. 1C); the herring-fed mice had lower very-low-density lipoprotein (VLDL)-cholesterol concentrations throughout the study period $(\mathrm{P}=0.006$ and 0.041 , respectively), as well as a lower LDL-cholesterol concentration at week $8(\mathrm{P}=0.001)$. Furthermore, plasma HDL-cholesterol concentration was lower at week 16 in the beef-fed compared to the herring-fed mice $(\mathrm{P}=0.004)$.

Hepatic lipid profiling. There were no differences in hepatic TAG (44.4 \pm 3.7 vs. $35.2 \pm 3.14 \mathrm{mg} / \mathrm{g}$ liver dry weight for herringand beef-fed mice, respectively) or total cholesterol $(2.12 \pm 0.04$ vs. $2.02 \pm 0.06 \mathrm{mg} / \mathrm{g}$ liver dry weight for herring- and beef-fed mice, respectively) content between the 2 diet groups. In the hepatic TAG fraction there was no difference between herring- and beef-fed mice in the proportion of SFA (38.5 \pm 1.2 and $36.0 \pm 1.1$ mole $\%$, respectively). The proportion of MUFA was lower in the hepatic TAG obtained from the herring-fed mice compared with the beef-fed mice $(\mathrm{P}=0.001 ; 43.2 \pm 2.8$ vs. 59.0 mole\%, respectively). The proportion of $n-3$ PUFA in hepatic TAG from the herring-fed mice was higher compared to the beef-fed mice $(\mathrm{P}=0.001 ; 13.3 \pm 2.0$ vs. $5.01 \pm 1.04$ mole\%, respectively). There was no dietary effect on the hepatic TAG content of n-6 PUFA between the groups (NS; 4.81 \pm 0.37 and $4.12 \pm 0.72$ mole $\%$, herring- vs. beef-fed mice, respectively). In Fig. 2A the differences in the hepatic TAG fraction at the level of individual fatty acids are displayed. The differences between the diet groups in MUFA were associated with a lower proportion of oleic acid (18:1n-9) and gondoic acid (20:1n-9) in the herring-fed mice. The higher proportion of n-3 PUFA in hepatic TAG from the herring-fed mice was due to an increased incorporation of EPA, docosapentaenoic acid (22:5n-3) and docosahexaenoic acid (DHA; 22:6n-3).

The proportion of SFA in hepatic phospholipids was higher in the herring-fed mice compared with the beef-fed mice $(\mathrm{P}<0.001 ; 47.0 \pm 0.3$ vs. $42.9 \pm 0.5$ mole $\%$, respectively) and the proportion of MUFA was lower $(\mathrm{P}<0.001 ; 13.5 \pm 0.5$ vs. $22.1 \pm 0.6$ mole $\%$ for the herring- vs. the beef-fed mice, respectively). Hepatic phospholipids from the herring-fed mice contained a higher proportion of $n-3$ PUFA $(\mathrm{P}<0.001 ; 39.5 \pm 0.4$ vs. 35.0 \pm 0.4 mole $\%)$ and a lower proportion of n-6 PUFA $(\mathrm{P}<0.001 ; 10.4 \pm 0.4$ vs. $22.1 \pm 1.2$ mole $\%$ for herring- vs. beef-fed mice, respectively). The lower panel in Fig. $2 \mathrm{~B}$ shows that the herring-fed mice had an increased proportion of stearic acid (18:0), and lower proportion of palmitoleic (16:1n-7), vaccinic $(18: 1 n-7)$ and oleic acids in hepatic phospholipids. This was associated with a lower proportion of the n- 6 PUFA; linoleic (LA; 18:2n-6), dihomo- $\gamma$-linolenic (20:3n-6) and arachidonic acids (AA; 20:4n-6), and a higher proportion of EPA and DHA in hepatic phospholipids obtained from the herring-fed mice.

Atherosclerosis. Ultrasound measurements of the aortic arch at week 12 showed no difference in atherosclerotic plaque area between the 2 diet groups. There was however a tendency in the aortic arch for a lower intima-media thickness $(\mathrm{P}=0.127$; $0.15 \pm 0.01$ vs. $0.16 \pm 0.01 \mathrm{~mm}$ ) and reduced plaque formation in the herring-fed mice compared with the beef-fed mice $\left(\mathrm{P}=0.197 ; 0.13 \pm 0.01\right.$ vs. $\left.0.15 \pm 0.01 \mathrm{~mm}^{2}\right)$. The plaque formation of the thoracic artery was too small to be accurately measured by ultrasound. In addition, the level of obesity interfered with the ultrasound measurements. Fig. 3 shows the plaque formation in the aorta at week 16 measured by en face histology. The plaque areas in the aortic arch were significantly lower in the herring-fed mice $(\mathrm{P}=0.007)$. There was no difference in plaque areas in the thoracic and abdominal aorta measured by en face histology at week 16 between the 2 diet groups.

Adipocyte size. The effect of diet on adipocyte size in the mesenteric and the epididymal fat depots was investigated. An average of $637 \pm 171$ adipocytes was analysed per sample (range 103-1186). The herring-fed mice had smaller adipocytes in the epididymal fat depot compared with mice given the beef $\operatorname{diet}(\mathrm{P}=0.009 ; 82 \pm 4$ vs. $94 \pm 3 \mu \mathrm{m}$, respectively). There was no significant difference in adipocyte size in the mesenteric depot ( $83 \pm 2$ vs. $87 \pm 3 \mu \mathrm{m}$, for herring and beef-fed mice, respectively). 
A. Triacylglyceride fraction

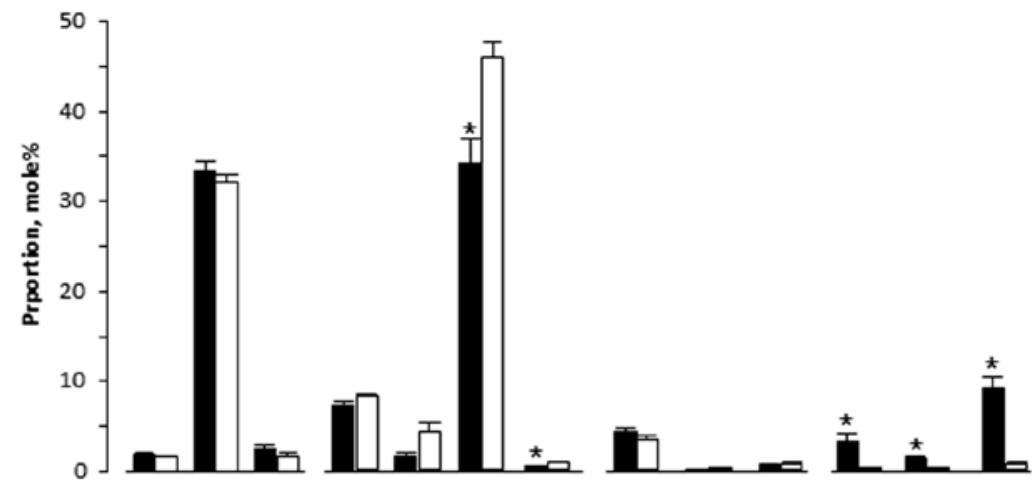

B. Phospholipid fraction

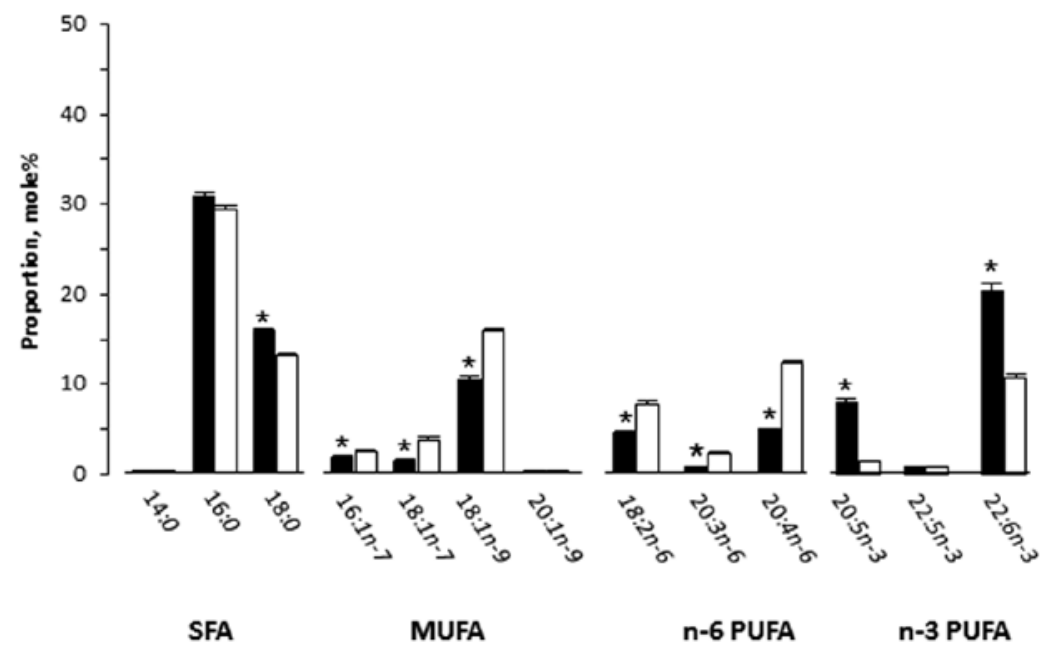

Figure 2. Fatty acid composition of TAG (a) and phospholipid (b) fractions in livers from herring-fed mice (black bars) or beef-fed mice (open bars) after 16 weeks of diet. Data are shown as mean \pm SE, $n=6$ per diet group. Significant differences were tested using unpaired t-test and corrected for multiple comparisons according to Bonferroni-Holm ( $\mathrm{P}<0.0036$ first comparison).
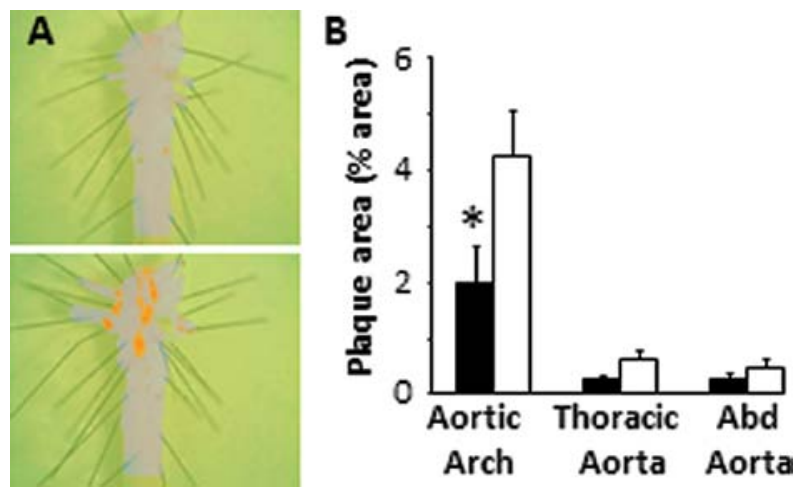

Figure 3. Dietary effects on atherosclerosis evaluated by en face histology (a). The top image is derived from a herring-fed mouse and the lower from a beef-fed mouse. The herring-fed mice (black bars) had lower amount of plaque formation in the aortic arch compared with mice given the beef diet (open bars) (b). The bars represent mean \pm SE ( $n=14$ and 13 for beef and herring, respectively). Significant difference was tested using unpaired t-test and shown as ${ }^{*}(\mathrm{P}<0.05)$.

\section{Discussion}

These data show that $L d l r^{--}$mice fed an energy-dense diet supplemented with herring had lower plasma concentra- tions of TAG and VLDL-cholesterol, and higher plasma HDL-cholesterol concentrations compared with mice fed the same diet but supplemented with lean beef. The differences in plasma lipid profile were consistent with lower amount of aortic arch plaques in the herring-fed mice compared with the beef-fed mice. The findings are in agreement the finding that plaque size in male $L d l r^{-/}$mice was positively correlated to plasma TAG and VLDL-cholesterol concentrations, and negatively to plasma HDL-cholesterol concentrations (33). The question is which bioactive compounds are present in herring but not in beef that could mediate such effects and by which mechanisms? In this section the well-known effects of longchain n-3 PUFAs on CVD will be discussed, along with effects of taurine and choline, both present at higher amounts in the herring than in the beef diet.

The dose of EPA and DHA in the herring diet in this study is comparable to previous studies of $L d l r^{-/}$mice using fish oil (34-36), which ranged between 6 and $14 \mathrm{~g}$ of EPA+DHA compared to $11 \mathrm{~g}$ EPA+DHA per kilogram of diet used in this study. However, several other parameters differed between the studies; dietary content of cholesterol and lipids, study time and choice of reference diets, rendering direct comparisons on outcome on atherosclerotic development more difficult. Despite these differences in study design, all 3 reported a 
reduction in atherosclerosis (34-36). In this study, fatty acid analysis confirmed higher proportion of long-chain n-3 PUFA in livers from the herring-fed mice compared with the beef-fed mice. In particular, the herring-supplemented diet resulted in a higher proportion of EPA in the hepatic TAG and phospholipid fractions. The higher proportion of EPA in phospholipids from the herring-fed mice and of AA from the beef-fed mice could be of relevance to atherosclerotic progression as EPA and AA compete for the same enzymes for the synthesis of different eicosanoids (37). Eicosanoids derived from EPA, often referred to as anti-inflammatory, inhibit platelet aggregation and vasoconstriction, as well as reduce the recruitment and attachment of leukocytes to the vessel wall (37). The higher proportion of hepatic EPA in the herring-fed mice is an indirect support to our previous finding that plasma EPA was negatively correlated to subclinical atherosclerosis in 61-year-old men (17).

The herring-supplemented diet contained more than twice the amount of taurine, a free organic acid, compared with the beef-supplemented diet. It has been shown that both short (38) and long-term (39) high dietary intake of taurine in mice reduced serum VLDL/LDL-cholesterol concentrations. In the latter study, taurine treatment was associated with reduced aortic valve plaque formation (39). However, these studies used much higher daily doses of taurine than this present study; 10 to 170 times higher than the taurine present in the herring and beef diets. A clinical study showed that combined intake of the long-chain n-3 PUFA (EPA and DHA) and taurine had larger effects on total, LDL- and HDL-cholesterol concentrations than intake of long-chain n-3 PUFA alone (11). This proposed synergy effect between taurine and long-chain n-3 PUFA, present in herring but not in beef muscle, could be an explanation to the finding of maintained HDL-cholesterol and lower VLDL-cholesterol concentrations in the herring-fed mice. In the transcriptome study performed on a subset of the mice ( $\mathrm{n}=3$ per diet group) we found that hepatic Cyp7al transcript levels were higher in the herring-fed compared with the beef-fed mice (24). That Cyp7al is a promising candidate as a mediator for the herring-induced effects is supported by the finding that $L d l r^{-/}$mice overexpressing Cyp $7 a l$ were resistant to diet-induced hypercholesterolemia (40).

A metabolomic study in $L d l r^{-/}$mice revealed a disturbed choline metabolism, when the mice were fed a high fat/cholesterol/cholate diet for 12 weeks (41). The authors suggested that the changes in choline metabolism could be related to the development of atherosclerosis. In contrast to the present study, the plasma TAG concentrations were reduced in the mice fed the experimental diet despite the high fat and cholesterol levels (41). Choline is required for cell signalling and VLDL secretion from hepatocytes (42). Dietary choline as well as phosphatidylcholine has been shown to affect hepatic cholesterol homeostasis in rats, including increased excretion of cholesterol via the bile $(43,44)$. The diets in this study were not supplemented with choline since both beef and fish muscle contain high amounts of total choline (45). In fact, herring muscle was reported to contain more than 50\% higher amount of phospholipids and phosphatidylcholine than beef (46). The presence of phospholipids in fish presents a putative difference in the health effects of fish intake compared with dietary supplementation of fish oil, since lipids in fish oil are predominantly in the form of TAG. Hence, the reduced plasma cholesterol concentrations in the herring-fed mice could also be a consequence of higher dietary intake of phosphatidylcholine.

From week 7, the herring-fed mice had an increased body weight compared to the beef-fed mice while the relative body fat mass was similar between the groups. Still, adipocyte size in the epididymal depot was reduced in herring-fed mice indicating that components in this diet may influence adipose tissue resulting in hypertrophic or hyperplastic growth response. This is in agreement with a previous study in rats showing that retroperitoneal fat cell size was reduced after 4 weeks high fat/high sucrose diet supplemented with long chain n-3 PUFA (47). In comparison with large adipocytes, small adipocytes expressed lower levels of pro-inflammatory adipokines such as serum amyloid A (48). Serum amyloid A is known to bind to HDL and is proposed to negatively affect reverse HDL-cholesterol transport (49). It is therefore, possible that development of hyperplastic adipose tissue in the herring-fed $L d l r^{-/}$mice could be related to the lower formation of plaques in these mice.

These data suggest that nutritional effects on health are not only dependent on the macronutrient composition of the diet, but also on the food items included in the diet. Note that the protein source of the reference diet, i.e. lean beef, is also considered to be a healthy food choice. It is therefore likely that intake of herring has an added value compared with beef due to its high content of several known bioactive food compounds such as long-chain n-3 PUFA, taurine and phosphatidylcholine. Further studies are needed to positively identify the mechanisms by which these bioactive compounds, individually or in combination, confer their beneficial effects on lipid homeostasis and vascular health. From a clinical point of view, these data also suggest that patients with familial hypercholesterolemia would benefit from an increased dietary intake of fish.

\section{Acknowledgements}

The technical support of Birgitta Oden is gratefully acknowledged. Lena Amrot Fors, AstraZeneca, is acknowledged for the lipoprotein profile analyses. This study was financed by grants from the Region of Västra Götaland; Stiftelsen Olle Engkvist, Byggmästare; the Swedish National Board of Fisheries (EU Structural Funds); the Swedish Medical Research Council (Project No. 12206); grants from the LUA/ALF agreement.

\section{References}

1. Joint WHO/FAO Expert Consultation: WHO Technical Report Series 916: Diet, Nutrition and the Prevention of Chronic Diseases. WHO, Geneva, 2003.

2. Brunner EJ, Mosdol A, Witte DR, et al: Dietary patterns and $15-\mathrm{y}$ risks of major coronary events, diabetes, and mortality. Am J Clin Nutr 87: 1414-1421, 2008.

3. Heidemann C, Schulze MB, Franco OH, van Dam RM, Mantzoros CS and Hu FB: Dietary patterns and risk of mortality from cardiovascular disease, cancer, and all causes in a prospective cohort of women. Circulation 118: 230-237, 2008.

4. Menotti A, Kromhout D, Blackburn H, Fidanza F, Buzina R and Nissinen A: Food intake patterns and 25-year mortality from coronary heart disease: cross-cultural correlations in the Seven Countries Study. The Seven Countries Study Research Group. Eur J Epidemiol 15: 507-515, 1999.

5. Tourlouki E, Matalas AL and Panagiotakos DB: Dietary habits and cardiovascular disease risk in middle-aged and elderly populations: a review of evidence. Clin Interv Aging 4: 319-330, 2009. 
6. He K, Song Y, Daviglus ML, et al: Accumulated evidence on fish consumption and coronary heart disease mortality: a metaanalysis of cohort studies. Circulation 109: 2705-2711, 2004.

7. Kromhout D, Bosschieter EB and de Lezenne Coulander C: The inverse relation between fish consumption and 20-year mortality from coronary heart disease. N Engl J Med 312: 1205-1209, 1985.

8. Engelfriet P, Hoekstra J, Hoogenveen R, Buchner F, van Rossum C and Verschuren M: Food and vessels: the importance of a healthy diet to prevent cardiovascular disease. Eur J Cardiovasc Prev Rehabil 17: 50-55, 2010.

9. Balk EM, Lichtenstein AH, Chung M, Kupelnick B, Chew P and Lau J: Effects of omega-3 fatty acids on serum markers of cardiovascular disease risk: a systematic review. Atherosclerosis 189: 19-30, 2006

10. Kris-Etherton PM, Harris WS and Appel LJ; the American Heart Association, Nutrition Committee: Fish consumption, fish oil, omega-3 fatty acids, and cardiovascular disease. Circulation 106 2747-2757, 2002

11. Elvevoll EO, Eilertsen KE, Brox J, et al: Seafood diets: hypolipidemic and antiatherogenic effects of taurine and n-3 fatty acids Atherosclerosis 200: 396-402, 2008

12. Gunnarsdottir I, Tomasson H, Kiely M, et al: Inclusion of fish or fish oil in weight-loss diets for young adults: effects on blood lipids. Int J Obes (Lond) 32: 1105-1112, 2008.

13. Thorsdottir I, Tomasson H, Gunnarsdottir I, et al: Randomized trial of weight-loss-diets for young adults varying in fish and fish oil content. Int J Obes (Lond) 31: 1560-1566, 2007.

14. Undeland I, Lindqvist $\mathrm{H}$, Chen-Yun Y, et al: Seafood and health: what is the full story? In: Marine functional food. Luten JB (ed). Wageningen Academic Publishers, Wageningen, The Netherlands, pp17-87, 2009.

15. Berr C, Akbaraly T, Arnaud J, Hininger I, Roussel AM and Barberger-Gateau P: Increased selenium intake in elderly high fish consumers may account for health benefits previously ascribed to omega-3 fatty acids. J Nutr Health Aging 13: 14-18, 2009.

16. Lindqvist HM, Langkilde AM, Undeland I and Sandberg AS: Herring (Clupea harengus) intake influences lipoproteins but not inflammatory and oxidation markers in overweight men. Br J Nutr 101: 383-390, 2009.

17. Lindqvist HM, Sandberg AS, Fagerberg B and Hulthe J: Plasma phospholipid EPA and DHA in relation to atherosclerosis in 61-year-old men. Atherosclerosis 205: 574-578, 2009.

18. Ishibashi S, Goldstein JL, Brown MS, Herz J and Burns DK: Massive xanthomatosis and atherosclerosis in cholesterol-fed low density lipoprotein receptor-negative mice. J Clin Invest 93 1885-1893, 1994

19. Teupser D, Persky AD and Breslow JL: Induction of atherosclerosis by low-fat, semisynthetic diets in LDL receptor-deficien C57BL/6J and FVB/NJ mice: comparison of lesions of the aortic root, brachiocephalic artery, and whole aorta (en face measurement). Arterioscler Thromb Vasc Biol 23: 1907-1913, 2003.

20. Schreyer SA, Lystig TC, Vick CM and LeBoeuf RC: Mice deficient in apolipoprotein E but not LDL receptors are resistant to accelerated atherosclerosis associated with obesity. Atherosclerosis 171: 49-55, 2003.

21. Varret M, Abifadel M, Rabès JP and Boileau C: Genetic heterogeneity of autosomal dominant hypercholesterolemia. Clin Genet 73 $1-13,2008$.

22. Summers RM, Andrasko-Bourgeois J, Feuerstein IM, et al: Evaluation of the aortic root by MRI: insights from patients with homozygous familial hypercholesterolemia. Circulation 98: $509-518,1998$

23. Tahvanainen E, Molin M, Laakso J, et al: Interrelationships between low density lipoprotein receptor defect, serum fatty acid composition, and serum cholesterol concentration. J Nut Biochem 10: 360-366, 1999.

24. Nookaew I, Gabrielsson BG, Holmäng A, Sandberg AS and Nielsen J: Identifying molecular effects of diet through systems biology: influence of herring diet on sterol metabolism and protein turnover in mice. PLoS One 5: e12361, 2010

25. Lee CM, Trevino B and Chaiyawat M: A simple and rapid solvent extraction method for determining total lipids in fish tissue. J AOAC Int 79: 487-492, 1996.

26. Sjogren K, Hellberg N, Bohlooly-Y M, et al: Body fat content can be predicted in vivo in mice using a modified dual-energy $\mathrm{X}$-ray absorptiometry technique. J Nutr 131: 2963-2966, 2001.

27. Björnheden T, Jakubowicz B, Levin M, et al: Computerized determination of adipocyte size. Obes Res 12: 95-105, 2004.
28. Gan LM, Grönros J, Hägg U, et al: Non-invasive real-time imaging of atherosclerosis in mice using ultrasound biomicroscopy. Atherosclerosis 190: 313-320, 2007.

29. Bourghardt J, Bergstrom G, Krettek A, Sjoberg S, Boren J and Tivesten A: The endogenous estradiol metabolite 2-methoxyestradiol reduces atherosclerotic lesion formation in female apolipoprotein E-deficient mice. Endocrinology 148: 4128-4132, 2007.

30. Folch J, Lees M and Sloane Stanley GH: A simple method for the isolation and purification of total lipids from animal tissues. J Biol Chem 226: 497-509, 1957.

31. Kaluzny MA, Duncan LA, Merritt MV and Epps DE: Rapid separation of lipid classes in high yield and purity using bonded phase columns. J Lipid Res 26: 135-140, 1985.

32. Holm S: A simple sequentially rejective multiple test procedure. Scand J Statist 6: 65-70, 1979.

33. VanderLaan PA, Reardon CA, Thisted RA and Getz GS: VLDL best predicts aortic root atherosclerosis in LDL receptor deficient mice. J Lipid Res 50: 376-385, 2009.

34. Saraswathi V, Gao L, Morrow JD, Chait A, Niswender KD and Hasty AH: Fish oil increases cholesterol storage in white adipose tissue with concomitant decreases in inflammation, hepatic steatosis, and atherosclerosis in mice. J Nutr 137: 1776-1782, 2007.

35. Wang S, Wu D, Matthan NR, Lamon-Fava S, Lecker JL and Lichtenstein AH: Reduction in dietary omega- 6 polyunsaturated fatty acids: eicosapentaenoic acid plus docosahexaenoic acid ratio minimizes atherosclerotic lesion formation and inflammatory response in the LDL receptor null mouse. Atherosclerosis 204: 147-155, 2009.

36. Zampolli A, Bysted A, Leth T, Mortensen A, De Caterina R and Falk E: Contrasting effect of fish oil supplementation on the development of atherosclerosis in murine models. Atherosclerosis 184: 78-85, 2006

37. Anderson BM and Ma DW: Are all n-3 polyunsaturated fatty acids created equal? Lipids Health Dis 8: 33, 2009.

38. Chen W, Suruga K, Nishimura N, Gouda T, Lam VN and Yokogoshi H: Comparative regulation of major enzymes in the bile acid biosynthesis pathway by cholesterol, cholate and taurine in mice and rats. Life Sci 77: 746-757, 2005.

39. Murakami S, Kondo-Ohta $\mathrm{Y}$ and Tomisawa K: Improvement in cholesterol metabolism in mice given chronic treatment of taurine and fed a high-fat diet. Life Sci 64: 83-91, 1999.

40. Ratliff EP, Gutierrez A and Davis RA: Transgenic expression of CYP7A1 in LDL receptor-deficient mice blocks diet-induced hypercholesterolemia. J Lipid Res 47: 1513-1520, 2006.

41. Cheng KK, Benson GM, Grimsditch DC, Reid DG, Connor SC and Griffin JL: A metabolomic study of the LDL receptor null mouse fed a high-fat diet reveals profound perturbations in choline metabolism that are shared with ApoE null mice. Physiol Genomics: Mar 2, 2010 (Epub ahead of print).

42. Li Z and Vance DE: Thematic review series: glycerolipids. Phosphatidylcholine and choline homeostasis. J Lipid Res 49: 1187-1194, 2008.

43. LeBlanc MJ, Brunet S, Bouchard G, et al: Effects of dietary soybean lecithin on plasma lipid transport and hepatic cholesterol metabolism in rats. J Nutr Biochem 14: 40-48, 2003.

44. LeBlanc MJ, Gavino V, Pérea A, Yousef IM, Lévy E and Tuchweber B: The role of dietary choline in the beneficial effects of lecithin on the secretion of biliary lipids in rats. Biochim Biophys Acta 1393: 223-234, 1998.

45. Zeisel SH, Mar MH, Howe JC and Holden JM: Concentrations of choline-containing compounds and betaine in common foods. J Nutr 133: 1302-1307, 2003

46. Weihrauch J and Son YS: Phospholipid content of foods. J Am Oil Chem Soc 60: 1971-1978, 1983.

47. Raclot T, Groscolas R, Langin D and Ferre P: Site-specific regulation of gene expression by $n-3$ polyunsaturated fatty acids in rat white adipose tissues. J Lipid Res 38: 1963-1972, 1997.

48. Jernas M, Palming J, Sjoholm K, et al: Separation of human adipocytes by size: hypertrophic fat cells display distinct gene expression. FASEB J 20: 1540-1542, 2006.

49. Hua S, Song C, Geczy CL, Freedman SB and Witting PK: A role for acute-phase serum amyloid A and high-density lipoprotein in oxidative stress, endothelial dysfunction and atherosclerosis. Redox Rep 14: 187-196, 2009. 